\title{
Prevalence of postpartum depression and association with risk factors in a tertiary care hospital
}

\author{
Gita Guin, Sarika Rawat*
}

Department of Obstetrics and Gynecology, NSCB Medical College, Jabalpur, Madhya Pradesh, India

Received: 09 January 2018

Accepted: 03 February 2018

\section{*Correspondence:}

Dr. Sarika Rawat,

E-mail: sarika0406@gmail.com

Copyright: (C) the author(s), publisher and licensee Medip Academy. This is an open-access article distributed under the terms of the Creative Commons Attribution Non-Commercial License, which permits unrestricted non-commercial use, distribution, and reproduction in any medium, provided the original work is properly cited.

\begin{abstract}
Background: Postpartum depression also known as postnatal depression is a non-psychotic depressive disorder of variable severity and it can begin as early as after delivery and can persist indefinitely if untreated. The objective of this study was to determine the prevalence of postpartum depression by Edinburgh postnatal depression scale and to evaluate the factors predisposing to postpartum depression.

Methods: The present prospective observation study was conducted in the Department of Obstetrics and Gynaecology, Netaji Subhash Chandra Bose Medical College, Jabalpur from $1^{\text {st }}$ March 2015 to $31^{\text {st }}$ August 2016. Participants were screened for postnatal depression using EPDS. A risk factor questionnaire that covered key sociodemographic and obstetrics factors were also completed by all the subjects. Main outcome measure: prevalence of a score of 13 or higher, on the EPDS. The data of the present study was recorded into computer and after proper validation, error checking, coding and decoding, the data was compiled and analysed using the SPSS Window, Appropriate univariate and bivariate analysis were carried out using the fisher exact test or Chi-square test for categorical variables.

Results: The present study concludes that the prevalence of postpartum depression is $12.8 \%$ (64/500) amongst postnatal women admitted of Obstetrics unit of NSCB Medical College, Jabalpur (Madhya Pradesh) since the prevalence of an EPDS score $\geq 13$ (which is suggestive of PPD) was found in a significant proportion of women, screening for PPD is indicated in all postpartum subjects to identify and promptly treat these women. Identification of a clear association between certain risk factors and PPD will lead to a prompter diagnosis of PPD.
\end{abstract}

Keywords: EPDS, PPD, Screening

\section{INTRODUCTION}

Postpartum depression also known as postnatal depression is a non-psychotic depressive disorder of variable severity and it can begin as early as after delivery and can persist indefinitely if untreated. The illness can cause distress and impair a mother's ability to carry out her normal tasks, care for herself and care of her baby. ${ }^{1-3}$ The prevalence of postpartum depression, worldwide varies from $0.5 \%$ to $60.8 \%$ in the first 12 months of delivery using self-reported questionnaire. ${ }^{4}$ Edinburgh Postnatal Depression Scale [EPDS] is one of the most successful screening tools for PPD developed by Kendell et al in Edinburgh Scotland which is the result of the first major research on PPD over 30 years ago. ${ }^{5,6} \mathrm{~A}$ review of 37 validation studies of the EPDS had shown a highly variable sensitivity from 34 to $100 \%$ and a specificity of 44 to $100 \% .^{7}$ An EPDS score of $\geq 13$ is strongly suggestive of PPD. Postpartum depression is associated with A past history of psychiatric illness, illiteracy, low socioeconomic status, lack of good antenatal care, nuclear family, and inability to breast feed have a positive association with PPD. An in depth psychosocial analysis of PPD reveals a positive 
association with past history of PPD, family history of psychiatric illness, childcare stress, anxiety during pregnancy, stressful life events during pregnancy, and low levels of partner support. ${ }^{8-10}$

\section{METHODS}

The present prospective observational study was conducted in Department of Obstetrics and Gynaecology NSCB Medical College and Hospital, Jabalpur (Madhya Pradesh) from $1^{\text {st }}$ March 2015 to $31^{\text {st }}$ August 2016. Sample size was calculated by fallowing formula:

$\mathrm{n}=[\mathrm{DEFF} \times$ No $(1-\mathrm{p})] /\left[\left(\mathrm{d}^{2} / \mathrm{Z}^{2}{ }_{1-\alpha / 2} \times(\mathrm{N}-1)+\mathrm{p} \times(1-\mathrm{p})\right]\right.$

Where,

$\mathrm{Z}=1.96$ for $99 \%$ confidence interval,

$\mathrm{N}=$ population size (5000),

$\mathrm{p}=$ assumed probability (prevalence),

$\mathrm{d}=$ marginal absolute error $=5 \%$

DEFF (designed effect for cluster survey) $=1$

500 subjects were selected after a simple random sampling technique and informed consent for participation in this study was taken. All the subjects were explained about the PPD and importance of scoring done by pretested structured questionnaires (EPDS) for the screening of PPD and its future consequences. An informed consent was obtained from eligible subjects. A detailed assessment was done and pretested structured questionnaires (EPDS) was filled, which include demographic data, obstetric history, associated co morbidities, past and family history of psychiatric illness, EPDS scoring followed by questionnaires for predisposing factors of PPD.

Demographic data were collected as age, socio-economic status, education level, locality (rural and urban), antenatal check-up (booked and unbooked), type of family (nuclear, joint). Relevant obstetrics history was taken as mode of delivery, and sex of child. Specific co morbidity presented in any subjects like anaemia (mild, moderate, severe), pre-eclampsia, eclampsia was assessed. Any relevant history of past psychiatric illness was noted, along with any family history of same. EPDS is the screening tool for PPD, 10 items self-report scale specifically designed to screen for postpartum depression in community samples. Each item is scored on a 4-point scale (from 0-3), with a total score ranging from 0 to 30 . The items, written in the past tense, include questions related to maternal feelings during the past 7 days. $^{6}$

Questions 1, 2 and 4 (without an*) are scored 0, 1, 2 or 3 with top box scored as 0 and the bottom box scored as 3 .

Questions 3, 5-10 (marked with an*) are reverse scored, with the top box scored as a 3 and the bottom box scored as 0 . Maximum score: 30 .
Mothers who score above 13 are likely to be suffering from a depressive illness of varying severity. Predisposing factors were assessed in form of questionnaires to evaluate the association between the predisposing factors and prevalence of PPD.

\section{Statistical analysis}

Data were entered in MS Office. The prevalence of PPD was estimated. Results were analyzed applying the Chi square test and ODDS ratio was calculated for each qualitative variable to evaluate the significance of association of risk factor with PPD.

The relative risk for each statistically significant risk factor was calculated. $\mathrm{P}$ value $<0.05$ were considered statistically significant.

\section{RESULTS}

Of the 500 women studied 64 scored $\geq 13$ on the Edinburgh postnatal depression scale. Prevalence of PPD is $12.8 \%$. A total of 500 women were recruited in the study by simple random sampling technique. The demographic details are shown in Table 1.

Table 1: Demographic details of subjects.

\begin{tabular}{|c|c|c|c|c|c|}
\hline Variables & N/D & $\%$ & $X^{2}$ & OR & P-value \\
\hline \multicolumn{6}{|l|}{ Age } \\
\hline$<20$ & $0 / 12$ & 0 & \multirow{6}{*}{20.31} & & \multirow{6}{*}{$<0.05$} \\
\hline $20-25$ & $25 / 282$ & 8.9 & & & \\
\hline $26-30$ & $20 / 135$ & 14.8 & & & \\
\hline $31-35$ & $20 / 57$ & 32.3 & & & \\
\hline $36-40$ & $4 / 12$ & 33.3 & & & \\
\hline$>40$ & $0 / 2$ & 0 & & & \\
\hline \multicolumn{6}{|c|}{ Education status } \\
\hline illiterate & $37 / 240$ & 15.4 & \multirow{2}{*}{2.80} & \multirow{2}{*}{1.5} & \multirow{2}{*}{$>0.05$} \\
\hline literate & $27 / 260$ & 10.38 & & & \\
\hline \multicolumn{6}{|l|}{ Locality } \\
\hline Rural & $42 / 228$ & 18.40 & \multirow{2}{*}{11.8} & \multirow{2}{*}{0.38} & \multirow{2}{*}{$<0.001$} \\
\hline Urban & $22 / 272$ & 8.1 & & & \\
\hline \multicolumn{6}{|c|}{ Socio-economic status } \\
\hline Lower & $38 / 238$ & 16.2 & & & \\
\hline $\begin{array}{l}\text { Middle } \\
\text { and } \\
\text { upper }\end{array}$ & $26 / 262$ & 9.92 & 4.51 & 0.56 & $<0.05$ \\
\hline
\end{tabular}

After adjustment for all significant postnatal variables risk factors like antenatal check-up, gender of baby, family history of psychiatric illness, past history of psychiatric illness, negative breast feeding, type of family, mode of delivery, child care stress, adverse life event, inadequate family and social support, lack of partner support, anxiety during pregnancy, complication during pregnancy statically significant which were shown in Table 2. 
Table 2: Relation of risk factors to EPDS.

\begin{tabular}{|c|c|c|c|c|c|}
\hline & $E P D S \geq 13$ & EPDS $<13$ & $\chi^{2}$ & Odd ratio & $P$ value \\
\hline \multicolumn{6}{|c|}{ Antenatal check-up } \\
\hline Booked & 19 & 187 & \multirow{2}{*}{4.02} & \multirow{2}{*}{1.07} & \multirow{2}{*}{$<0.05$} \\
\hline Unbooked & 45 & 249 & & & \\
\hline \multicolumn{3}{|c|}{ Type of family } & \multirow{3}{*}{5.19} & \multirow{3}{*}{$0.48(0.93-0.23)$} & \multirow{3}{*}{$<0.05$} \\
\hline Nuclear & 51 & 285 & & & \\
\hline Joint & 13 & 151 & & & \\
\hline \multicolumn{3}{|c|}{ Mode of delivery } & \multirow{3}{*}{9.37} & \multirow{3}{*}{$2.26(3.98-1.28)$} & \multirow{3}{*}{$<0.01$} \\
\hline NVD & 33 & 308 & & & \\
\hline LSCS & 31 & 128 & & & \\
\hline \multicolumn{3}{|c|}{ Gender of baby } & \multirow{3}{*}{7.54} & \multirow{3}{*}{$2.13(3.88-1.28)$} & \multirow{3}{*}{$<0.05$} \\
\hline Male & 22 & 230 & & & \\
\hline Female & 42 & 206 & & & \\
\hline \multicolumn{3}{|c|}{ Breast feeding } & \multirow{3}{*}{15.63} & \multirow{3}{*}{0.26} & \multirow{3}{*}{$<0.001$} \\
\hline No & 14 & 30 & & & \\
\hline Yes & 50 & 406 & & & \\
\hline \multicolumn{3}{|c|}{ Past history of psychiatric illness } & \multirow{3}{*}{17.44} & \multirow{3}{*}{$5.20(13.03-1.97)$} & \multirow{3}{*}{$<0.001$} \\
\hline No & 54 & 421 & & & \\
\hline Yes & 10 & 15 & & & \\
\hline \multicolumn{3}{|c|}{ Family history of psychiatric illness } & \multirow{3}{*}{21.56} & & \\
\hline No & 49 & 409 & & $4.64(9.73-2.13$ & $<0.0001$ \\
\hline Yes & 15 & 27 & & & \\
\hline Child care & & & & & \\
\hline No & 26 & 310 & 23.52 & $3.60(6.43-2.03)$ & $<0.001$ \\
\hline Yes & 38 & 126 & & & \\
\hline Anxiety du & & & & & \\
\hline No & 27 & 313 & 22.47 & $3.49(6.22-1.97)$ & $<0.001$ \\
\hline Yes & 37 & 123 & & & \\
\hline Adverse lif & & & & & \\
\hline No & 31 & 361 & 38.19 & $5.12(9.20-2.84)$ & $<0001$ \\
\hline Yes & 33 & 75 & & & 0.001 \\
\hline Inadequate & I support & & & & \\
\hline No & 29 & 261 & 4.85 & $1.80(3.17-1.03)$ & \\
\hline Yes & 35 & 175 & & & $<0.05$ \\
\hline Poor partn & & & & & \\
\hline No & 26 & 270 & 10.48 & $2.38(4.23-1.35)$ & $<0.001$ \\
\hline Yes & 38 & 166 & & & $<0.001$ \\
\hline Medical ill & & & & & \\
\hline No & 09 & 233 & 34.65 & $7.01(16.50-3.32)$ & $<0.0001$ \\
\hline Yes & 55 & 203 & & & \\
\hline
\end{tabular}

Demographically prevalence of PPD $48.1 \% \quad(n=50 / 500)$ were observed in age group of 31-40 years. Mean age of studied subjects with postpartum depression was 25.84 year. The prevalence of PPD was $18.4 \%$ amongst the rural population $(\mathrm{n}=228)$ while it is $8.1 \%$ amongst the urban population $(n=272)$. By this data association of postpartum depression with the subjects of rural area can be determined. This difference was statistically significant $(\mathrm{P}<0.001)$. The prevalence of PPD in lower socioeconomic group was $16.2 \%(\mathrm{n}=238)$ as compared middle class and upper class. Thus, the low socioeconomic status contributes to the development of PPD. ( $\mathrm{P}<0.05)$ indicate comparison between lower socioeconomic group and other. $9.2 \%(\mathrm{n}=19)$ in subjects who had regular antenatal visits $(\mathrm{n}=206)$ were less likely to suffer from PPD as compared to subjects who had no antenatal visits $15.3 \%(n=45)$.

In present study it was found that unbooked subjects had 1.78 times more chances of PPD. This may be due to antenatal visits made them aware about the health issues, giving them opportunity to share their problems and clear the doubts and fears of pregnancy. Which was statistically significant $(\mathrm{P}<0.05)$. The prevalence of PPD were $15.2 \%$ amongst subjects from nuclear family $(\mathrm{n}=$ 336) while it is $7.9 \%$ amongst subjects were belonging from joint family. $(\mathrm{p}<0.05)$ indicate the comparison between nuclear and joint families. The prevalence of 
PPD 9.7\% amongst the subjects who delivered NVD $(n=341)$ while it is $19.5 \%$ amongst the subjects who underwent caesarean section. Subjects who underwent LSCS had 2.26 times more chances of having PPD.

$(\mathrm{p}<0.01)$ indicate the comparison between subjects who delivered NVD and who underwent LSCS. This was statistically significant. The prevalence of PPD $8.7 \%$ amongst subjects who had male child total $(n=252)$ and $16.9 \%$ amongst subjects who had female child $(\mathrm{n}=248)$. The male to female ratio was similar but the association of depression was strongly seen in favour of birth of female child which indicate that inspite of various mass publicity of survival of female child the depression is highly prevalent amongst this category.

The difference was statistically significant $(\mathrm{p}<0.05)$ prevalence of PPD amongst subjects exclusively breast feeding is significantly lower than those who fail to initiate breast feeding of their babies $(p<0.001)$. It was observed positive association of prevalence of PPD with subjects who had anaemia. The difference in prevalence between those having no anaemia with those having anaemia is statistically highly significant $(\mathrm{P}<0.0001)$.

Pre-eclampsia subjects had 2.12 times more chances of developing PPD which was statically significant $(p<0.005)$. Eclampsia subjects had 6.03 times more chances of developing PPD. This was statically highly significant ( $p<0.0001)$. Past H/O PPD significantly increases (5.2 times greater risk) the chances of having PPD. Subjects who had family history of PPD had 4.64 times greater risk of developing PPD $(\mathrm{OR}=4.64) 95 \% \mathrm{CI}$ $(9.73-2.13) \quad(p<0.0001)$. Family history of psychiatric disorder must therefore be elicited from all pregnant patients. Almost $32.8 \%$ of subjects have stress of child care at some point or other. Of them $23.2 \%$ had PPD when compared to those who have no such stress due to readily available help at home $(\mathrm{PPD}=7.7 \%)$. This difference is statically highly significant $(\mathrm{p}<0.001) \chi^{2}=$ $23.52 ;$ OR $=3.60[6.43-2.03] .32 \%$ of subjects had history of anxiety during pregnancy. Of them $23.1 \%$ subjects had postpartum depression. This was statistically highly significant $\chi 2=22.47$; $(\mathrm{P}<0.001) \mathrm{OR}=3.49$ (6.221.97). The prevalence of PPD was more $30.6 \%$ amongst subjects who had adverse life event $(n=108)$ than the subjects who had no adverse life events due to decrease confidence and altered mental threshold level and they become more emotionally liable. $(\mathrm{P}<0.0001)$ $\mathrm{OR}=5.12(9.20-2.84)$.

The prevalence of PPD was $16.7 \%$ amongst the subjects who had inadequate social support $(n=210)$. This is possibly because social support from family members and others provides emotional and instrumental support which were protective by buffering the impact of life stress on emotional wellbeing of mother. The difference is statistically significant $(\mathrm{p}<0.05)$ OR $=1.80$ [3.171.03]. This study shows prevalence of PPD were observed less if subjects had their partner support this was probably because by encourage to participate actively in household tasks and infant care activities protects the mother from becoming overwhelmed $\chi^{2}=$ 10.48; $\mathrm{P}<0.001 \mathrm{OR}=2.38[4.23-1.35] .160$ subjects had history of complications during delivery and out of which $24(15 \%)$ subjects were observed with postpartum depression. Risk of development of PPD statistically was not significant associated with subjects had history of complication during delivery $(\mathrm{p}<0.143)$.

\section{DISCUSSION}

In the present study 500 subjects were selected by a simple randomization table, $64(12.8 \%)$ had postpartum depression. A similar study by Desai $\mathrm{N}$ et al reported prevalence of PPD $12.5 \% .{ }^{11}$ Swapan G et al in their study "postpartum depression in north Indian women: prevalence and risk factors" reported the prevalence of PPD at $15.8 \% .^{12}$

\section{Association of age with PPD}

The age wise analysis of studied subjects with PPD $(12.8 \%)$ shows the mean age to be $25.84 \pm 4.24$, while subjects without postpartum depression had a mean age of 24.19 \pm 3.70 ; thus, mean age was higher in PPD subjects and it was statistically significant $(\mathrm{p}<0.05)$. Risk of postpartum depression increases with the increasing age of the subjects, probably because older women have higher rates of pregnancy complications such as multiple births, hypertension and diabetes and their increasing social and family responsibilities made them irritable and anxious.

The study by Desai $\mathrm{N}$ et al found the mean age was 23.84 which is very similar to present study. ${ }^{11}$ Swapan G et al found the mean age of their subjects to be $24.62 \pm 3.7$ years. $^{12}$

\section{Association of education with PPD}

The present study shows that the prevalence of Postpartum depression to be $15.4 \%$ amongst illiterate group $(\mathrm{n}=240)$ and $11.9 \%(\mathrm{n}=101)$ amongst subjects educated up to primary school which was relatively higher than in subjects educated up to middle school. This was possibly because as education improves the ability to deal with stress of child bearing and employment improves.

It may be that the prevalence of PPD is lowest amongst the graduates due to the similar reasons. A similar study by Swapan G et al found $9.4 \%$ prevalence of PPD in subjects who had more than primary education. ${ }^{12}$

\section{Association of locality with PPD}

In the present study, $18.4 \%$ rural subjects had postpartum depression may be because they experience more adverse living conditions, poor health, low family 
and community support and poor access to quality health services than urban counterparts. The study by Lane, et al also found that the prevalence of PPD was more in rural areas. $^{13}$

\section{Association of socioeconomic status with PPD}

In the present study, $16.2 \%$ subjects belonging to lower socioeconomic strata were depressed $(\mathrm{P}<0.05)$ as compared to middle/upper socioeconomic class. The poor financial condition makes the family unable to fulfil basic needs and lead a healthy lifestyle; the new baby further straining the finances. Swapans $G$ study found a significantly high $(31.3 \%)$ prevalence of PPD in the lower SES. ${ }^{12}$

Similar studies by Nandi et al and Goyal et al also suggest that low socio-economic status contributes to the development of PPD. ${ }^{14,15}$

\section{Association of antenatal check-up with PPD}

In the present study unbooked subjects had 1.78 times more chances of PPD. This difference was statistically significant $\chi^{2}=4.02 ;(\mathrm{P}<0.05)$ indicating that antenatal visits may give women an opportunity to be aware about the health issues, share their problems and clear the doubts and fears of pregnancy. Similar observation was found in a study by Prabhu TR et al at $9.1 \%$ in those without proper antenatal care as compared to subjects who had regular antenatal visit $(3.1 \%) .{ }^{16}$

\section{Association of type of family with PPD}

In the present study, the prevalence of PPD was $15.2 \%$ amongst subjects from nuclear family $(\mathrm{n}=336)$ while it is $7.9 \%$ amongst subjects from joint family. Thus, positive association of postpartum depression was seen with nuclear families because women belonging to nuclear family have poor support from other family members and higher level of marital adjustment is needed as compared to joint families ( $\mathrm{p}<0.05)$.

In the study by Prabhu TR et al the prevalence was high in women from nuclear families $(9.4 \%)$ as compared to those from joint families $(1.2 \%){ }^{16}$ In the study by Swapan G et al too, PPD was more prevalent in women from nuclear families $(\mathrm{P}=0.15) \mathrm{OR}=1.74(0.76-3.98) .{ }^{12}$

\section{Association of mode of delivery with PPD}

Present study reveals that subjects who underwent LSCS had 2.26 times more chances of having PPD. This was statistically significant $(\mathrm{p}<0.01)$. Boyce, et al (1992) found a highly significant correlation between caesarean section and developing postpartum depression at 3 months. ${ }^{17}$ They reported that women within their study who had an emergency caesarean section had more than six times the risk of developing postpartum depression.

\section{Association of sex of baby with PPD}

In our study, the prevalence of PPD is 2.1 times higher amongst subjects who had given birth to a female child in present pregnancy. This strong association of depression of birth of female child with PPD (OR = 2.13) may indicate that in spite of all efforts to sensitize the public towards a more gracious welcome to the birth of a girl child, a daughter is still considered a burden and her birth may not be always welcome.

A study by Desai $\mathrm{N}$ et al found that subjects who had a female child had 5.487 times higher odds of getting depression than those having male child. ${ }^{11}$ Swapan $G$ et al also observed similar finding. ${ }^{12}$

\section{Association of breast feeding with PPD}

The prevalence of PPD amongst subjects exclusively breast feeding was significantly lower than those who fail to initiate breast feeding to their babies ( $p<0.001)$. Breast feeding gives a sense of satisfaction and completeness and also helps to better deal with the hormonal changes occurring after delivery of baby.

A study by Misri and colleagues observed a positive association between patients with PPD and cessation of breastfeeding. ${ }^{18}$ Fergerson and co-authors reported that a failed attempt at breastfeeding or early cessation of breastfeeding was found to be significantly associated with higher patient scores on the EPDS $(\mathrm{N}=72) .{ }^{19}$

\section{Association of past history of psychiatric illness or depression with PPD}

In present study we found that risk of PPD was 5.2 times higher in subjects with past history of depression, so every woman with such a history should have timely counselling, early recognition and treatment. The study by Swapan $G$ et al found that PPD risk was 8 times greater $(\mathrm{OR}=8.9)(\mathrm{p}<0.01)$ amongst women who had past history of psychiatric illness. ${ }^{12}$

Similar observations were made in a study by Johnstone et al, and Josefsson et al who found that a previous history of postpartum depression increased risk of developing postpartum depression in subsequent pregnancies. $^{20,21}$

\section{Association of family history of psychiatric illness with PPD}

In the present study, subjects with family history of PPD had 4.64 times greater risk of developing PPD. OR $=4.64$ (95\%, CI 9.73-2.13) which was statistically highly significant ( $\mathrm{p}<0.0001$ ). Similar observations were made by Prabhu TR et al who found that the prevalence of PPD was more in subjects who had family history of psychiatric illness $(21 \%)$ as compared to those who had no such family history $(8 \%){ }^{16}$ 


\section{Association of high risk pregnancies with PPD}

In the present study, significant association of postpartum depression with obstetrics complication like anemia, severe pre-eclampsia, eclampsia, still birth was found. O'Hara and Swain concluded that obstetric factors (preeclampsia, eclampsia anemia) had a small effect [0.26] on the development of postpartum depression. ${ }^{9}$ Josefsson et al reported a significant association between delivery complications and depression. ${ }^{21}$

\section{Evaluation of EPD Score in PPD}

The present study evaluated the various parameters on EPDS. It was found that postpartum depression strongly correlated with child care stress, anxiety during pregnancy, stressful life event, social support, partner support. Beck in his study found a significant correlation of PPD with prenatal anxiety, child care stress, lack of social support, adverse life events and history of previous depression. ${ }^{8}$ A similar association is seen in study by Swapan G et al. ${ }^{12}$

\section{CONCLUSION}

The prevalence of postpartum depression amongst postnatal women admitted of Obstetrics unit of NSCB Medical College, Jabalpur (Madhya Pradesh) at $12.8 \%$. Various predisposing factors like child care stress, anxiety during pregnancy, inadequate social support, stressful life events, and lack of partner support can be easily addressed by counselling of pregnant subjects and their families. Every antenatal clinic must have a separate section for counselling. The postnatal period during which the just delivered mothers are at high risk of developing PPD must be well covered by social workers to aid early identification of women likely to develop PPD. It is also important to address the stigma associated with psychiatric disorders.

\section{Recommendations}

The findings of the present study will be shared with all members of Obstetric Unit, Psychiatry Department and as well as all other related faculty of Medical College Hospital, Jabalpur to create awareness of the magnitude of psychiatric disorders in expectant and delivered mothers. I advocate, on the basis of my findings-

- Routine screening of postnatal mothers especially those with high risk factors.

- Training of Obstetricians to aid timely recognition of the symptoms of depression.

- Formulating policies integrating mental and reproductive health.

Funding: No funding sources

Conflict of interest: None declared

Ethical approval: The study was approved by the Institutional Ethics Committee

\section{REFERENCES}

1. Beck CT. Postpartum depression: it is not just the blues. Am J Nur. 2006;106(5):40-50.

2. Hatton DC, Harrison-hohner J, Coste S. Symptoms of postpartum depression and breast feeding. J Hum Lactation. 2005;21(4):444-9.

3. Lanes A, Kuk JL, Tamim H. Prevalence and characteristics of postpartum depression symptomatology among Canadian women: a crosssectional study. BMC Public Health. 2011;11(1):1.

4. Steiner M. Postpartum psychiatric disorders. Canadian J Psych. 1990;35(1):85-95.

5. Wisner KL, Chambers C, Sit DK. Postpartum depression: a major public health problem. JAMA. 2006;296(21):2616-8.

6. Cox JL, Holden JM, Sagovsky R. Detection of postnatal depression. Development of the 10-item Edinburgh postnatal depression scale. Br J Psych. 1987;150(6):782-6.

7. McQueen K, Dennis CL. Development of a postpartum depression best practice guideline: a review of the systematic process. J Nurs Care Qual. 2007;22(3):199-204.

8. Beck CT. Predictors of postpartum depression: an update. Nursing Res. 2001;50(5):275-85.

9. O'hara MW, Swain AM. Rates and risk of postpartum depression: a meta-analysis. Int Rev Psych. 1996;8(1):37-54.

10. Stewart DE, Robertson E, Dennis CL, Grace SL, Wallington T. Postpartum depression: literature review of risk factors and interventions. Toronto: University Health Network Women's Health Program for Toronto Public Health. 2003.

11. Desai N, Mehta RY, Ganjiwale J. Study of prevalence and risk factors of postpartum depression. Natl J Med Res. 2012;2:2249-95.

12. Gupta S, Kishore J, Mala YM, Ramji S, Aggarwal R. Postpartum depression in north Indian women: Prevalence and risk factors. J Obstet Gynaecol India. 2013;63(4):223.

13. Lane B, Roufeil LM, Williams S, Tweedie R. It's just different in the country: postnatal depression and group therapy in a rural setting. social work in health care. 2002;34(3-4):333-48.

14. Nandi T, Bugdayci R, Dundar P, Sumer H, Sasmaz T. Risk factors for depression in the first postnatal year. Social Psych Psych Epidemiol. 2005;40(9):725-30.

15. Goyal D, Murphy SO, Cohen J. Immigrant Asian Indian women and postpartum depression. J Obstet Gynecol Neonatal Nurs. 2006;35:98-104.

16. Prabhu TR, Asokam TV, Rajeshwari A. Post-partum psychiatric illnesses. J Obstet Gynecol India. 2005;55(4):329-32.

17. Boyce PM, Todd AL. Increased risk of postnatal depression after emergency. Med J Australia. 1992;157(3):172-4. 
18. Misri S, Sinclair DA, Kuan AJ. Breast-feeding and postpartum depression: is there a relationship? Canadian J Psych. 1997;42(10):1061-5.

19. Fergerson SS, Jamieson DJ, Lindsay M. Diagnosing postpartum depression: can we do better? Am J Obstet Gynecol. 2002;186(5):899-902.

20. Johnstone SJ, Boyce PM, Hickey AR, Morris-Yates $\mathrm{AD}$, Harris MG. Obstetric risk factors for postnatal depression in urban and rural community samples. Aus New Zealand J Psych. 2001;35(1):69-74.
21. Josefsson A, Angelsiöö L, Berg G, Ekström CM, Gunnervik C, Nordin C, et al. Obstetric, somatic, and demographic risk factors for postpartum depressive symptoms. Obstet Gynecol. 2002;99(2):223-8.

Cite this article as: Guin G, Rawat $S$. Prevalence of postpartum depression and association with risk factors in a tertiary care hospital. Int J Reprod Contracept Obstet Gynecol 2018;7:1094-100. 